\title{
NOTAS SOBRE EL SPRAWL URBANO Y SANTIAGO*
}

\author{
Robert Bruegmann
}

\begin{abstract}
A cuatro años de la primera edición del libro Sprawl: A Compact History, su autor comenta en estas páginas el estado actual de la discusión sobre expansión urbana (sprawl). Luego de resumir algunos de los principales contenidos de su obra de 2005 (la historia del sprawl urbano en el mundo, así como la historia de las objeciones al sprawl y los resultados de las políticas dirigidas a detenerlo o impedirlo), Robert Bruegmann pasa revista a los estudios más recientes, muchos de los cuales ponen en tela de juicio, cuando no refutan derechamente, supuestos que hasta hace poco se tenían por verdades establecidas sobre la descentralización y la expansión urbanas. Respecto a Santiago, Bruegmann se refiere a algunos de los problemas que, a su entender, tendrían que superarse para que pueda llegar a transformarse en una ciudad del mundo desarrollado.
\end{abstract}

Palabras clave: Sprawl (expansión urbana); historia urbana; planificación urbana; gentrification (renovación urbana); Santiago de Chile. Recibido: noviembre de 2008. Aceptado: diciembre de 2008.

Robert Bruegmann. Ph. D., University of Pennsylvania. Actualmente es profesor de la Escuela de Arquitectura y del Programa de Planificación y Políticas Urbanas de la Universidad de Illinois, en Chicago. También ha enseñado en las universidades de Pennsylvania, Philadelphia College of Arts, MIT y Columbia.

* Traducción al castellano de Alberto Ide para Estudios Públicos. 
匹 2005 University of Chicago Press publicó mi libro Sprawl: A Compact History ${ }^{1}$. En él sostuve, contradiciendo de plano la opinión establecida, que el sprawl no era un fenómeno reciente, ni particularmente estadounidense, y que tampoco era algo necesariamente malo. Si bien lo escribí en un estilo que yo pretendía que fuera accesible, se trata de una obra académica en la que se exponen algunas ideas complejas y que contiene una gran cantidad de notas a pie de página. Para sorpresa de todos, en especial mía, el libro se transformó en una suerte de best seller académico que llamó la atención tanto de la prensa especializada como de la prensa general en todo el mundo. No tardaron en aparecer nuevas ediciones de la obra y se habló de la posibilidad de traducirla a varios otros idiomas².

Como consecuencia de la enorme difusión alcanzada por el libro, pasé gran parte de los dos años siguientes viajando por el mundo, desde Boston hasta Beijing, dictando conferencias sobre el sprawl y prestando asesoramiento a diversos grupos y organismos gubernamentales. Una de las visitas más recientes, como asimismo más interesantes, fue la que realicé a Santiago de Chile, por invitación de Alexander Galetovic, del Centro de Estudios Públicos. En el siguiente ensayo resumiré, en primer lugar, los principales argumentos del libro, y luego me referiré a algunas de las reacciones que ha despertado y a los nuevos desarrollos que ha habido desde su publicación. Por último agregaré algunos comentarios sobre Santiago.

\section{SPRAWL: UNA HISTORIA COMPACTA}

Lo cierto es que la fuerza inspiradora para escribir este libro me llegó durante los años setenta, cuando trabajaba en mi tesis sobre urbanismo en el París del siglo XIX. Por cierto que en ese entonces me encontraba vivien-

\footnotetext{
${ }^{1}$ Los lectores encontrarán información detallada sobre las principales publicaciones acerca del sprawl, al igual que sobre la documentación en que se basan los argumentos que expongo en este artículo, en el texto y en las notas de mi libro. Si bien la bibliografía sobre el sprawl es muy extensa, se ha concentrado mayormente en los desarrollos recientes de una sola ciudad o de un país en particular. Mi libro fue el primero en analizar a fondo este tema, abarcando un período y un área geográfica mucho más amplios. Entre los importantes libros publicados en el último tiempo que han intentado referirse a los temas tratados en este artículo pueden mencionarse Edge City (1991), de Joel Garreau; Cities Without Cities: An Interpretation of the Zwischenstadt (2003), de Thomas Sievert; Cities for the New Millennium (2001), de Marcial Echenique y Andrew Saint, y Laws of the Landscape: How Policies Shape Cities in Europe and America (1999), de Pietro Nivola.

${ }^{2}$ Resulta curioso, aun cuando nadie ha propuesto una edición en español, que en estos momentos se esté traduciendo al chino.
} 
do y realizando mis investigaciones en la zona central de París, el único sector con el que la mayoría de los turistas está familiarizado. Sin embargo, cada vez que me trasladaba al aeropuerto para volar de regreso a los Estados Unidos, me llamaba la atención ver un paisaje suburbano que no era diferente del que se observa al aproximarse al aeropuerto de Filadelfia, de Chicago o de Toronto.

Al principio se trató de una mera curiosidad intelectual. Cuando acudí a la biblioteca para averiguar lo que los académicos y otros estudiosos habían escrito al respecto, me sorprendió descubrir un estante tras otro repleto de libros sobre la zona céntrica de París o de Nueva York, pero casi ninguna obra sobre el vasto territorio suburbano donde, ya en los años setenta, habitaba la enorme mayoría de la población urbana. Comencé a escribir lo que pensé sería un libro sencillo sobre la descentralización de las ciudades con el paso de los años. Pero hacia mediados de los años noventa sucedió algo inesperado. Durante el auge económico vivido en aquella época comencé a notar que el término sprawl se empleaba cada vez con mayor frecuencia. No era un concepto nuevo, pues sabía que se remontaba por lo menos a la década de 1950. Aun así, de pronto me pareció verlo utilizado de manera generalizada tanto en publicaciones académicas como en revistas populares.

Las objeciones al sprawl parecían clasificarse en cuatro categorías: económicas, sociales, ambientales y estéticas. Los asentamientos de baja densidad diseminados en zonas periféricas eran considerados, en primer lugar, económicamente ineficientes. Quienes lo creían así señalaban que las viviendas unifamiliares emplazadas en terrenos amplios resultaban más costosas, debido a las calles, sistemas de alcantarillado y toda la infraestructura que requerían, que las urbanizaciones de mayor densidad. En segundo lugar, se daba por sentado que el sprawl era un fenómeno socialmente pernicioso. No sólo había, supuestamente, un menor grado de interacción social entre los habitantes de los vecindarios periféricos de baja densidad, sino que también se argumentaba que con la expansión suburbana emprendida por familias de clase media los habitantes más pobres quedaban aislados en el centro de las ciudades, por lo menos en el caso de Norteamérica. En tercer lugar, también se pensaba que el sprawl suburbano ocupaba una cantidad excesiva de terreno, creaba problemas ambientales, como la contaminación causada por los automóviles, y aumentaba la superficie de terrenos impermeables que dificultan el retorno de las aguas a los acuíferos. Y por último, existía la opinión de que el sprawl y los suburbios en general eran irremediablemente antiestéticos. 
Llegué a la conclusión de que no podía escribir un libro sobre la expansión suburbana sin abordar este término (sprawl) y las ideas implícitas en él. Con todo, resultaba obvio que el término en sí era sumamente problemático. Por ejemplo, cuando la mayoría de los estadounidenses escuchaban esta palabra, su primera reacción era asociarla por lo general a una creciente congestión del tránsito. La manera usual en que se expresaba esta noción era que con el traslado de la gente a sectores cada vez más alejados del centro, aumentaba la distancia de los desplazamientos y, por ende, también aumentaban los niveles de congestión y de contaminación.

A primera vista esto parecía verosímil, pero cuando comencé a examinar los datos reales descubrí que la realidad era distinta. Así por ejemplo, si los detractores del sprawl tenían razón, una ciudad de muy baja densidad como Kansas City, con una población de aproximadamente 9 habitantes por héctarea en su zona urbanizada, debería exhibir un alto grado de congestión ${ }^{3}$. Sin embargo, ocurre que en Kansas City el problema de la congestión vehicular es bastante leve, y no es difícil advertir por qué. A medida que la ciudad se descentralizó, no sólo los habitantes sino además las empresas se trasladaron a zonas donde fuese posible construir nuevos caminos y autopistas capaces de soportar un alto nivel de tráfico. De este modo, Kansas City presenta uno de los tiempos de desplazamiento promedio más bajos entre las ciudades más prósperas del mundo.

En el otro extremo del espectro, si analizamos el caso de un área urbana densa y relativamente compacta como Tokio-Yokohama, cuya densidad superior a 44 habitantes por hectárea es una de las mayores entre todas las ciudades de altos ingresos, comprobaremos que, incluso disponiendo del que tal vez sea el mejor sistema de transporte del mundo, la congestión de tránsito se está volviendo abrumadora, y la duración de los viajes es

${ }^{3}$ En este trabajo, salvo especificación en contrario, todas las cifras relativas a población, superficie de terrenos y densidad se refieren a zonas urbanizadas. Se trata de una unidad de medida utilizada por las oficinas del censo de muchos gobiernos de todo el mundo como definición funcional de la metrópolis, en contraste con aquella basada en las divisiones arbitrarias de las jurisdicciones gubernamentales, que podrían considerarse menores o mayores que el territorio ocupado efectivamente a densidades urbanas. Normalmente, la zona urbanizada incluye un casco urbano y todo el territorio inmediatamente adyacente, con una importante vía de enlace para retornar a la zona céntrica, y con una determinada densidad de población urbana, que suele fijarse en alrededor de 4 habitantes por hectárea, que es más o menos el nivel en el que resulta económicamente viable proporcionar servicios urbanos como agua potable municipal y tratamiento de aguas servidas. Éste es el único indicador verdaderamente útil para comparar las densidades urbanas en regiones metropolitanas enteras. Todas las cifras de población y densidad utilizadas en este trabajo provienen del excelente compendio que se encuentra en el sitio web www.demographia.com, que mantiene Wendell Cox. 
mucho mayor que en cualquier otra ciudad estadounidense. De hecho, en todo el mundo los desplazamientos más prolongados, las mayores congestiones de tránsito y los niveles de contaminación más elevados se encuentran casi siempre en las áreas urbanas más densas.

Eso me proporcionó una cuña de entrada al enorme caudal de publicaciones dedicadas a los "problemas" que supuestamente eran causados por el sprawl. A medida que me adentré en el tema me asombró comprobar hasta qué punto las opiniones establecidas parecían hacer caso omiso de lo que se puede observar efectivamente en terreno. Por añadidura, conforme avanzaba en mi trabajo sobre la historia del sprawl no tardé en descubrir que casi todo lo que se decía habitualmente sobre el tema era engañoso o completamente erróneo. Decidí que antes de analizar la historia de la descentralización urbana sería útil aclarar una serie de concepciones erróneas acerca del sprawl que se habían acumulado durante años.

El resultado de ese esfuerzo fue un libro dividido en tres partes. En la primera se analiza la historia del sprawl; en la segunda, las objeciones contra el sprawl, y en la tercera, los remedios para el sprawl.

\section{Primera parte: Historia del sprawl}

Como historiador presumí que mi primera tarea al escribir sobre el sprawl sería reconstruir su historia. La opinión más comúnmente aceptada era que se trataba de un fenómeno mayormente estadounidense que se remontaba al período posterior a la Segunda Guerra Mundial, y que fue impulsado por un impresionante aumento en el número de dueños de automóvil y en el uso privado de este medio de transporte. Sin embargo, esa idea no lograba convencerme porque la historia urbana me había enseñado que las ciudades, al menos desde la Revolución Industrial, habían tenido un proceso continuo de expansión hacia las afueras a medida que un medio de transporte sucedía a otro, lo cual permitió que las familias se establecieran en zonas cada vez más alejadas del centro, casi siempre con densidades inferiores a las observadas anteriormente. En ese proceso, el sprawl de una generación tendía a transformarse luego en la comunidad establecida y central de una zona posterior.

Uno de los principales obstáculos para escribir esta historia del sprawl fue el hecho de que no existiera una definición ampliamente aceptada. Muchas de las definiciones más frecuentes eran en extremo subjetivas. Para ciertas personas el sprawl se refería a un asentamiento de baja densi- 
dad. Para otras, no aludía a la densidad propiamente tal sino a los manifiestos trastornos causados por el desarrollo disperso. Así como para otras correspondía a un resultado estético, a un ambiente construido que era supuestamente monótono, desordenado, o ambas cosas a la vez.

Quedaba en claro que una de las razones por las que no existía una definición común era esta diversidad de reparos al sprawl formulados por activistas anti-sprawl. Otra era que, en caso de existir una buena definición del sprawl, ello resultaría sumamente incómodo para los que suscribían las nociones anti-sprawl, pues muchos de ellos tendrían que admitir que vivían en un vecindario de ese tipo. En suma, había intereses en juego para mantener la definición en términos lo suficientemente vagos como para que resultara inservible analíticamente.

Para los fines de escribir esta historia, decidí utilizar los elementos comunes a casi todas las definiciones de sprawl, esto es: un asentamiento con densidad menor que las observadas anteriormente y cuya construcción no se ciñe a un plan maestro global. Gradualmente descubrí que con esta definición el sprawl era tan antiguo como las propias ciudades. Y pronto quedó claro por qué. Desde los inicios de la historia urbana hasta no hace mucho, el gran inconveniente de las ciudades era la excesiva densidad. Para la mayoría de quienes residían en ciudades la vida urbana era una experiencia muy desagradable. Quienes vivían en los barrios atestados de las zonas más pobres de la ciudad no sólo habitaban un ambiente ruidoso, congestionado y sucio. También podían tener una esperanza de vida menor y un nivel de salud inferior al de sus conciudadanos más acaudalados, que vivían en espaciosas villas en la periferia urbana.

En vista de lo anterior, desde los comienzos de la historia urbana hasta nuestra era, cuando un nuevo grupo humano alcanza una situación económica suficientemente sólida para abandonar el casco urbano, ya sea de manera permanente, por un fin de semana o por una temporada, lo hace. Y cuando estas nuevas familias llegan a la periferia, quienes ya se habían establecido en las afueras con anterioridad se quejan amargamente. Esto, a su vez, provoca esfuerzos dirigidos a detener las futuras migraciones hacia las afueras. Los intentos por prohibir la dispersión de Londres, por ejemplo, se remontan por lo menos a la época de Isabel I, en el siglo XVI.

Tenemos gran cantidad de información acerca del sprawl en varias ciudades de la antigüedad. Por ejemplo, sabemos que en Roma los ciudadanos más acaudalados ocupaban una vasta extensión dentro del territorio amurallado, y dejaban una superficie relativamente exigua para que cientos de miles de individuos vivieran hacinados en bloques de viviendas en altura llamados insulae. También contamos con numerosos antecedentes sobre 
los suburbios romanos, que cubrían superficies muy extensas. De hecho, la palabra suburbio, que proviene de la combinación del prefijo latino sub con el vocablo urbs y significa "debajo o más allá de los muros”, la hemos heredado de los romanos. Disponemos de buena evidencia bibliográfica y concreta de cómo era la vida en esos lugares, por ejemplo en Herculano, en las afueras de Nápoles. También sabemos que había vastas zonas con asentamientos de aun menor densidad, que decidí llamar "exurbia”, situados más allá de los suburbios relativamente desarrollados. Un claro ejemplo de esto último es el amplio complejo de edificios y paisajes en la villa del emperador Adriano en Tívoli.

Con todo, la historia moderna del sprawl se inicia con el masivo crecimiento de las ciudades a partir de la Revolución Industrial. Londres, al constituirse en la ciudad más extensa y próspera del mundo occidental, fue la reina del sprawl. En el siglo XIX, por ejemplo, Londres se expandió rápidamente hacia los alrededores, cubriendo una enorme superficie de terrenos rurales con kilómetro tras kilómetro de modestas casas pareadas de ladrillo. Para las familias que se mudaron desde la congestionada zona céntrica hasta estas casas pareadas, ubicadas en zonas recientemente accesibles gracias al ferrocarril a vapor, esto era casi como estar en el paraíso. El hecho de tener su casita propia en un terreno que les pertenecía, amén de una estación ferroviaria cercana, les ofrecía algunos de los tipos de privacidad, movilidad y libertad de elección que otrora sólo estaban a disposición de los miembros más acaudalados y poderosos de la sociedad británica.

Por otra parte, para una poderosa elite artística e intelectual, estas casas pareadas de ladrillo eran algo espantoso. A su juicio, las nuevas poblaciones suburbanas no eran más que el resultado de la intervención de especuladores codiciosos que se apoderaban de cada penique rendido por cada metro cuadrado de terreno, al tiempo que destruían la hermosa campiña inglesa y creaban sectores antiestéticos y monótonos que —según pronosticaban con gran seguridad- dentro de una generación se transformarían en barriadas. Lo cierto es que, transcurrida una generación, los miembros de esa misma elite habían cambiado de opinión. Ahora consideraban que esas calles donde se alineaban las casas pareadas eran parte del antiguo y consolidado distrito central de Londres, y algo completamente distinto de las horribles edificaciones que en ese entonces estaban siendo levantadas en la periferia urbana.

La mejor manera que encontré para describir el proceso del sprawl fue mediante el uso de la gradiente de densidad. Este tipo de representación gráfica de las densidades de población, popularizado por los geógrafos británicos en los años cincuenta, señala la densidad en el eje vertical, y la 
distancia desde el centro en el eje horizontal ${ }^{4}$. Por ejemplo, hacia 1800, en la zona céntrica de Londres había más de 380 hab/ha. Pero esa densidad descendía bruscamente a medida que nos alejábamos del centro, llegándose a cifras de nivel rural a sólo veinte kilómetros de la catedral de San Pablo. Cada década posterior a 1800, conforme crecía gradualmente la población en condiciones de alejarse del sector céntrico, la densidad del centro disminuía, mientras aumentaba la densidad en la periferia. Desde entonces hasta ahora la gradiente de densidad de Londres se ha aplanado y ha disminuido, al igual que en prácticamente todas las demás ciudades del mundo más próspero donde exista algo semejante a un mercado del suelo y algún grado de libertad personal para escoger empleos o barrios residenciales. La tendencia hacia menores densidades en el casco urbano y hacia una expansión constante de la zona periférica ha sido tal vez el hecho más importante del desarrollo urbano de los últimos siglos en todo el mundo. Cada vez que ocurre un auge económico y más personas están en condiciones de trasladarse hacia áreas urbanas en la periferia, buena parte de ellas ha aprovechado la oportunidad de hacerlo.

Una de las conexiones que no había previsto fue la que descubrí entre el sprawl en las afueras de las ciudades y la gentrification (renovación) del casco urbano. Al usar el término gentrification no pretendo emitir ningún juicio de valor. Con él simplemente me refiero al reemplazo de un grupo de personas por otro con más dinero y poder. Al menos durante los dos últimos siglos, a medida que muchos de los ciudadanos más pobres han tenido la posibilidad de alejarse del casco urbano o se vieron inducidos a abandonarlo, el territorio que desocuparon quedó entonces disponible para ser renovado por una clase más acomodada, deseosa de aprovechar las zonas de interés cultural y social del centro de la ciudad.

El ejemplo más espectacular de lo anterior puede apreciarse en París durante el Segundo Imperio, cuando Napoleón III y el barón Haussman demolieron vastos sectores del centro de París, obligando a sus habitantes a trasladarse a vecindarios situados en las afueras de la ciudad y sus suburbios. Su lugar fue ocupado por familias mucho más acaudaladas que se instalaron en suntuosos edificios de departamentos recién construidos que se alineaban en flamantes bulevares bordeados de árboles. Esta gentrification del casco urbano, tal como ha ocurrido en la mayoría de los casos desde entonces hasta ahora, no se contrapuso al sprawl. Fue la otra cara de

${ }^{4}$ La gradiente de densidad fue popularizada por el geógrafo inglés Colin Clark. Véase su artículo “Urban Population Densities”, 1951, y su libro Population Growth and Land Use, 1977. 
la misma moneda. El proceso mediante el cual las personas de menores recursos llegaron a estar en condiciones de trasladarse hacia las afueras, o se vieron forzadas a hacerlo, creó las condiciones para que el centro fuera renovado.

Muchos han dado por sentado que las ciudades europeas han tenido un desarrollo diferente al de las ciudades estadounidenses y que en ellas el sprawl ha sido menos intenso. Desde luego es verdad que las ciudades europeas tienen zonas céntricas más densas y sus habitantes tienden a usar más el transporte público que los habitantes de las ciudades norteamericanas. Pero lo anterior se debe en gran medida a que por lo general ellas se desarrollaron mucho antes que las ciudades estadounidenses. Lo cierto es que el proceso ha sido muy semejante tanto en Europa como en Estados Unidos, sólo que con un desfase atribuible más que nada a la prosperidad. La trayectoria de la transición desde densos edificios de departamentos ubicados en el centro hasta viviendas unifamiliares situadas en las afueras, y desde el empleo del transporte público hasta el uso del automóvil ha sido casi la misma en Europa y en los Estados Unidos, salvo por un leve desfase. Así por ejemplo, el fuerte aumento en el número de propietarios de automóvil y del uso de este medio de transporte, que en Estados Unidos comenzó durante los años veinte del siglo pasado, sólo tuvo lugar en Europa a partir de los años cincuenta. La trayectoria seguida por la curva del gráfico en cada caso es prácticamente idéntica (véase Gráfico No 1 en página 217).

La única vez que este patrón de desarrollo evidenció claras diferencias fue inmediatamente después de la Segunda Guerra Mundial, cuando muchos países europeos, diezmados por el conflicto, les confirieron a los planificadores un grado de poder sin precedentes y se embarcaron en iniciativas de gran escala en las que los propios gobiernos emprendieron o financiaron ambiciosos proyectos de reconstrucción que incluían una gran cantidad de viviendas públicas, la mayoría de las veces en altura, situadas en los suburbios alrededor de lo que históricamente había sido el centro. Pero transcurrida una sola generación, tan pronto como Europa hubo levantado cabeza económicamente, la clase media comenzó a rehuir las viviendas públicas que habían sido construidas en los años inmediatamente posteriores a la Segunda Guerra Mundial y reanudó su éxodo histórico desde la ciudad hacia los suburbios. Tanto en Europa como en los Estados Unidos, esos grandes complejos habitacionales se transformaron las más de las veces en una alternativa de último recurso. 


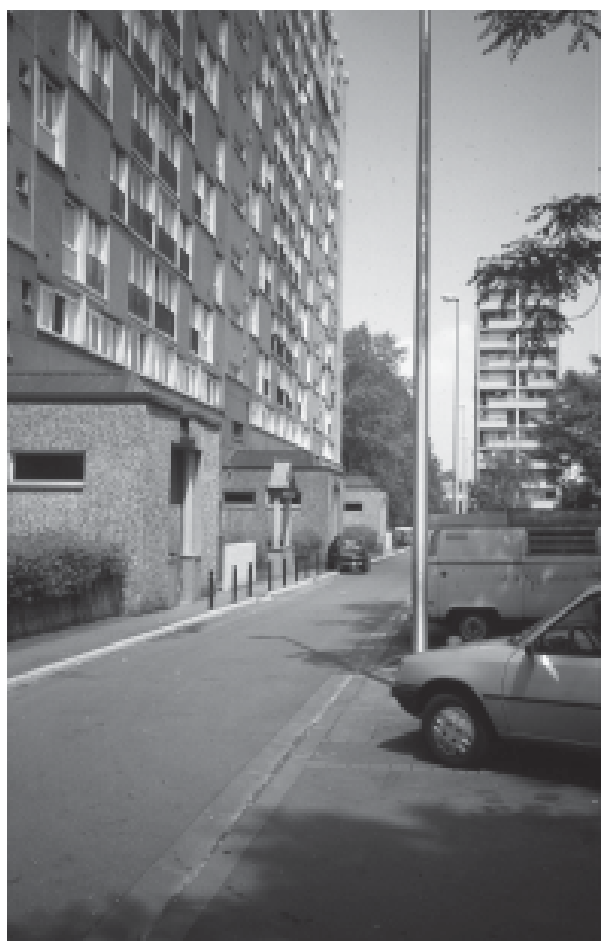

Foto 1. Bobigny: barrio de clase obrera en la periferia de París de la época de postguerra. Después de la Segunda Guerra Mundial, y por un breve período, Estados Unidos y Europa tuvieron un desarrollo urbano muy distinto entre sí. En parte por los daños ocasionados por la guerra, en parte por la diezmada economía, y en parte por una larga tradición de regulación del uso del suelo, los planificadores urbanos y otras autoridades gubernamentales europeas pudieron intervenir el desarrollo de la ciudad en forma más enérgica que sus homólogos estadounidenses. La mayoría de las nuevas viviendas alrededor de París fueron construidas directamente por entidades gubernamentales, o bien con importantes subsidios del Estado, mientras que la norma en los Estados Unidos, Canadá y Australia fue la vivienda unifamiliar financiada por el mercado. Sin embargo, una vez que Europa se recuperó de la guerra y aumentó el bienestar económico, los habitantes de las ciudades comenzaron a rechazar los grandes complejos habitacionales y a demandar viviendas unifamiliares. Las encuestas de opinión repetidamente han mostrado que la gran mayoría de la población urbana francesa, al igual que los habitantes de las ciudades en casi todos los países en que se realizan encuestas, preferiría vivir en casas aisladas unifamiliares. (@ The University of Chicago, 2005. Fotografía de Robert Bruegmann, 1999).

Muchos han creído que el sprawl se inició con el éxodo de las familias estadounidenses desde las ciudades hacia los suburbios durante los años cincuenta. Pero lo cierto es que sería más adecuado considerar ese éxodo como el fin de la fase más intensa del sprawl, que se extendió entre los años veinte y los años cincuenta del siglo XX, hasta que la superficie prome- 
GRÁFICO No 1: $\quad$ TRÁNSITO Y USO DEL AUTOMÓVIL EN EUROPA Y LOS ESTADOS UNIDOS
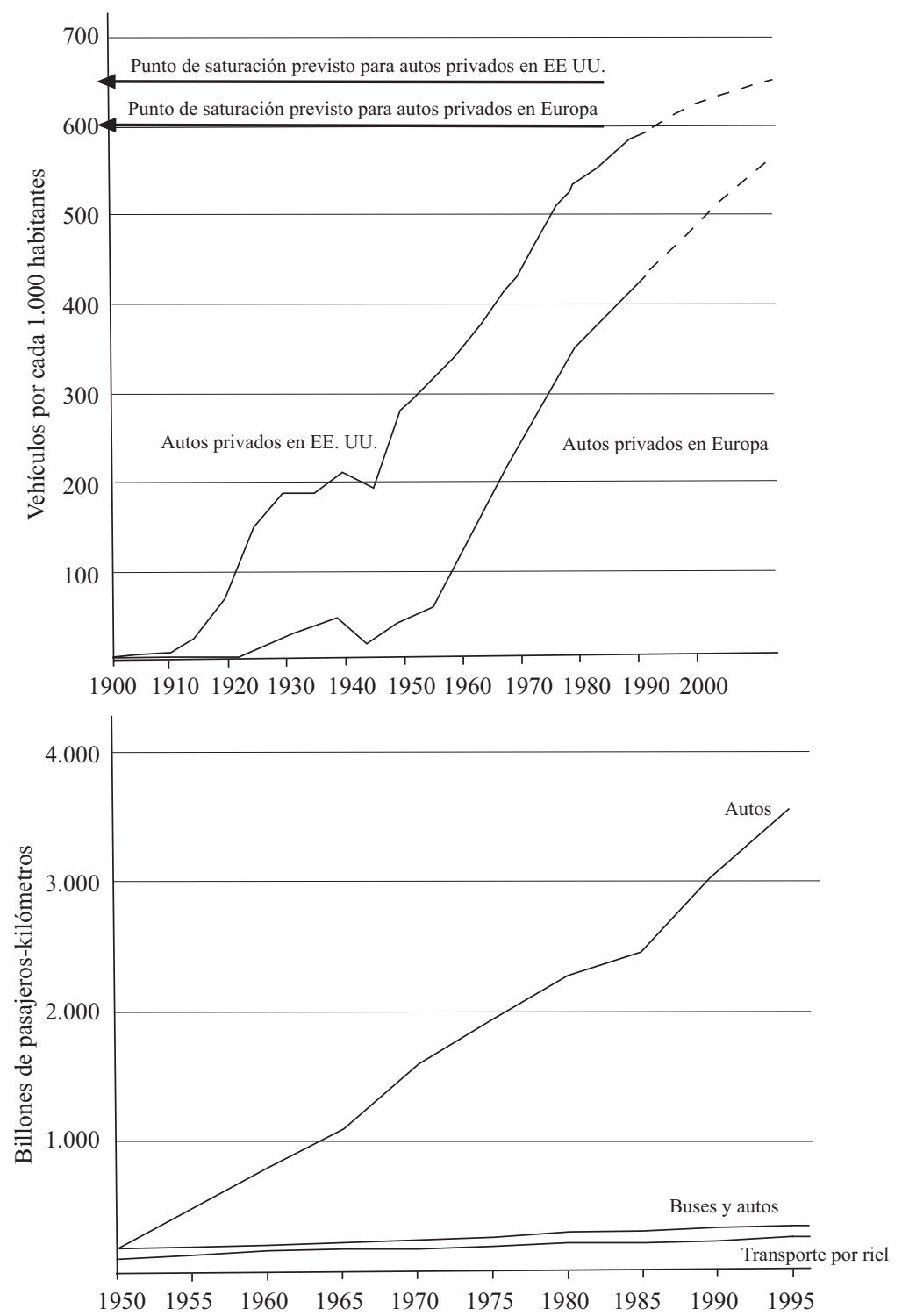

Nota: El panel superior muestra el aumento del número de automóviles en los Estados Unidos y Europa. El panel inferior muestra cómo el uso del autobús y el transporte por riel en Europa aparecen casi sin variaciones desde la segunda guerra mundial, mientras el uso del automóvil se ha incrementado enormemente. Los datos sugieren que Europa ha seguido una trayectoria muy similar a la de los EE.UU., salvo por un rezago en el tiempo. (Rehecho por Dennis McClendon y publicado en R. Bruegmann, Sprawl: A Compact History [University of Chicago Press, 2005], en base a Christian Gerondeau, Transport in Europe [Boston: Artec House, 1997].) 
dio del lote de una nueva vivienda en los suburbios estadounidenses y australianos alcanzó los $1.000 \mathrm{~m}^{2}$. Éstos fueron los sitios urbanos más grandes jamás conocidos, pero pronto su superficie comenzó a reducirse de manera importante. Hacia el año 2000 en los Estados Unidos la densidad de la mayoría de los suburbios en desarrollo había aumentado en forma significativa. Para muchos resulta más asombroso aun el hecho de que, en efecto, haya aumentado considerablemente la densidad global en numerosas zonas urbanas de rápido crecimiento y baja densidad de las regiones meridional y occidental de los Estados Unidos. Por ejemplo, la densidad del área urbanizada de Los Ángeles, considerada durante largo tiempo un ejemplo emblemático del sprawl, ha aumentado en más de un tercio desde la Segunda Guerra Mundial, mientras que la densidad de las ciudades antiguas de mayor superficie del noreste estadounidense y de Europa ha ido disminuyendo. Como resultado de lo anterior, Los Ángeles, con más de 24 hab/ha, es hoy en día la zona urbanizada más densa de la región comprendida por Estados Unidos y Canadá, y desde luego algo más densa que muchas zonas urbanizadas de Europa.

Uno de los asuntos más polémicos en torno al sprawl ha sido la discusión sobre sus causas. Muchos observadores han sostenido que es consecuencia del funcionamiento del mercado, de las decisiones adoptadas por las inmobiliarias y los fabricantes de automóviles. Sin embargo, esta explicación no es del todo satisfactoria. Después de todo, no hay motivos para que las inmobiliarias deseen construir en densidades bajas y no altas. En efecto, a lo largo de gran parte de la historia urbana se culpó al sector de la construcción de generar una densidad demasiado alta y no una densidad baja. Al fin y al cabo, lo lógico, en todo caso, sería que la industria inmobiliaria deseara construir más y no menos viviendas en una superficie determinada.

El argumento de que el sprawl fue causado por la industria automovilística es igualmente débil. Como hemos visto, el proceso de expansión de las ciudades hacia las afueras se encontraba en pleno desarrollo mucho antes de la invención del automóvil. Fue posible gracias a los carruajes privados tirados por caballos y más tarde el ferrocarril y el transporte público. Una vez más, Los Ángeles proporciona un interesante ejemplo al respecto. Ya hacia 1900 Los Ángeles se había transformado en una de las ciudades más extendidas del mundo, mucho antes de que la llegada del automóvil tuviese algún impacto importante, y su densidad ha aumentado de manera considerable desde 1945, precisamente durante la era en que se ha intensificado el uso del automóvil. De hecho, en lugar de considerar que el automóvil es la causa del sprawl, resultaría al menos igualmente lógico 
pensar que el deseo de vivir en áreas de baja densidad es una de las principales causas del crecimiento de la industria automovilística.

Algunos observadores quisieran culpar a las políticas públicas y no al mercado. Afirman que los gobiernos que han construido carreteras, proporcionado servicios públicos y ofrecido incentivos tributarios para adquirir una vivienda propia, han permitido no sólo que la población se disperse sino que, además, han creado poderosos alicientes para que esto ocurra. Y señalan que todo lo anterior equivale a un subsidio para erigir nuevos complejos de viviendas en la periferia en perjuicio del casco urbano. No obstante, ninguno de esos argumentos resulta muy convincente. En todo el mundo se da el proceso de dispersión de la población hacia las afueras de las ciudades, independientemente de quién esté financiando la infraestructura y de si hay o no incentivos para optar por la vivienda propia en lugar de pagar arriendo.

Si existe una variable que, al parecer, permita cuando menos rastrear el origen del sprawl y predecirlo, ella es simplemente el bienestar económico. Si bien yo jamás afirmaría que la prosperidad económica es la causa del sprawl, es efectivo que, al menos en el pasado, cada vez que ha mejorado la situación económica de las personas, muchas de ellas han querido disfrutar de un mayor grado de movilidad, privacidad y libertad de elección, y que para la mayor parte de la población, en particular los sectores menos acomodados, este deseo se ha cumplido de manera más satisfactoria con patrones de asentamiento de menor densidad en terrenos de precios más bajos situados en las afueras de las áreas metropolitanas.

\section{Segunda parte: \\ Reseña histórica de las objeciones al sprawl}

Así como parece existir una correlación bastante directa entre las grandes oleadas de sprawl y los períodos de auge económico, así también las objeciones al sprawl han seguido un patrón similar. Cada vez que una nueva legión de personas ha estado en condiciones de abandonar la ciudad, se han escuchado las vociferantes quejas de otros individuos molestos por los cambios que este éxodo trae aparejado. Las lamentaciones de este tipo son quizás tan antiguas como los propios suburbios y las ciudades. Como hemos señalado, esas quejas quedaron de manifiesto en la Gran Bretaña del siglo XIX, cuando miembros de la aristocracia terrateniente y de la elite artística e intelectual condenaron la existencia de grandes extensiones de casas pareadas suburbanas construidas para dotar de viviendas a una clase media inglesa en proceso de rápida expansión. 
Las objeciones a la situación imperante en el Londres del siglo XIX provenían principalmente de personas que miraban con desdén el comportamiento de aquellos a quienes consideraban socialmente inferiores. Un ejemplo particularmente ilustrativo de esta actitud fue un comentario del duque de Wellington acerca del ferrocarril, invención que permitió la expansión a gran escala de ciudades como Londres. Él denunciaba el hecho de que este medio de transporte "no [hacía] más que alentar a los ciudadanos comunes a trasladarse innecesariamente de un lugar a otro" 5 . Las quejas de este tenor se han mantenido hasta nuestros días. El término sprawl es rara vez usado por quienes creen vivir en un área de ese tipo. Quienes viven ahí son otras personas, en particular aquellas que, según los que usan el término, tienen menos sentido común y un gusto menos desarrollado.

La propia palabra "sprawl", como sustantivo que se refiere a patrones urbanos, no fue, como la mayoría ha llegado a creer, una invención estadounidense de la época posterior a la Segunda Guerra Mundial. Tal parece que empezó a ser de uso habitual en Gran Bretaña durante los años inmediatamente posteriores a la Primera Guerra Mundial, y su empleo entre las dos guerras mundiales dio pie para emprender la primera de las tres principales campañas dirigidas específicamente en contra del sprawl.

Durante el gran auge económico de los años veinte, cuando toda una nueva clase de ciudadanos estuvo en condiciones de trasladarse aun más hacia las afueras, internándose en la campiña que rodeaba las ciudades británicas, los paisajes suburbanos resultantes escandalizaron a muchos observadores. Para muchos arquitectos y planificadores urbanos que se consideraban a sí mismos sensibles a las sutilezas estéticas, los desarrollos de baja densidad de casas semiaisladas, que conformaban la mayoría de las urbanizaciones residenciales de esa época, les causaban especial desagrado. En su opinión, que reflejaba casi con exactitud la de individuos de su misma clase social en el siglo XIX, estas viviendas eran antiestéticas y monótonas, además de arruinar el paisaje de la hermosa campiña inglesa. Sus juicios eran compartidos por miembros de la aristocracia terrateniente y del mundo cultural de tendencia conservadora, quienes pertenecían a grupos como la Sociedad para la Conservación de la Inglaterra Rural.

La segunda campaña en gran escala en contra del sprawl fue emprendida tras la Segunda Guerra Mundial y se trató en gran medida de una iniciativa estadounidense. Puesto que Europa había sido tan violentamente azotada por la guerra, la mayor parte de la atención de los planificadores

${ }^{5}$ Este comentario del duque de Wellington es citado en Kenneth Jackson, Crabgrass Frontier: The Suburbanization of the United States, 1985. 


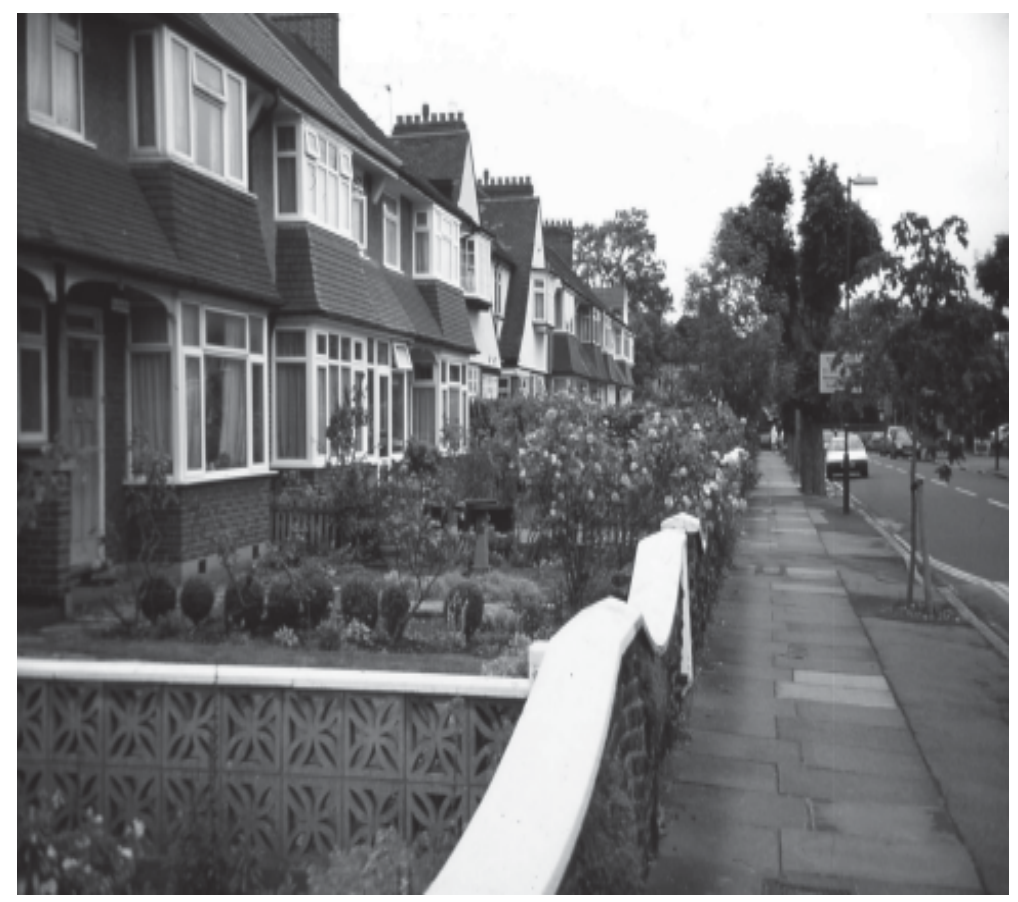

Foto 2: El sprawl del período de entreguerras.

Durante la década de 1920 la población del centro de Londres y sus alrededores creció cerca de $10 \%$. El área construida, sin embargo, se duplicó en una magnitud similar a las que se vieron en los Estados Unidos a fines del siglo XIX. Gran parte de las nuevas construcciones correspondían a casas pareadas como éstas en Merton Park, en el sur de Londres. Estas compactas y resistentes casas, como las hileras de casas idénticas del siglo XIX, eran miradas con desdén por la mayoría de la elite cultural británica, pero sumamente apreciadas por el común de los londinenses. (C The University of Chicago, 2005. Fotografía de Robert Bruegmann, 2002).

urbanos y de las autoridades de gobierno se concentró en crear nuevas viviendas en densidades bastante altas, el grueso de las cuales fueron construidas o financiadas por el Estado. El desarrollo suburbano, si bien se mantuvo, no fue objeto de mayor atención. En Norteamérica y Australia, por otra parte, el período de posguerra trajo consigo un espectacular crecimiento económico, el que a su vez reimpulsó la expansión de los suburbios. Como era de esperar, lo anterior desató otra ola de críticas contra el sprawl. La iniciativa más importante con que se abrió el fuego en esta campaña contra el sprawl fue la publicación en 1957 de un breve libro titulado The Exploding City, editado por un joven periodista llamado William H. Whyte para la revista Fortune. Se trataba de una denuncia, muy por el estilo del 
modelo británico, en contra del nuevo paisaje suburbano en los alrededores de las ciudades estadounidenses, pero utilizando ejemplos norteamericanos, particularmente la ciudad de Los Ángeles, como objeto de escarnio.

Más adelante sobrevino un caudal de publicaciones que condenaban el sprawl, ciñéndose a lo que para entonces se había transformado en una letanía habitual de objeciones: que era económicamente ineficiente, socialmente injusto, ambientalmente pernicioso y estéticamente horrible. Hubo una profusión de estudios que intentaron demostrar empíricamente que el sprawl era un problema, aunque también, en su momento, casi todos ellos fueron, uno por uno, enérgicamente refutados. Con todo, mirando hacia atrás pareciera que a pesar de todas esas argumentaciones sobre asuntos más o menos cuantificables, lo que en el fondo avivó la campaña en contra del sprawl en los Estados Unidos, durante la posguerra, fue una serie de posturas clasistas en torno a preocupaciones estéticas, simbólicas e incluso metafísicas, del mismo modo que esas inquietudes no cuantificables habían proporcionado el sustento emocional para la campaña británica del período de entreguerras.

Como ocurrió en todas las anteriores depresiones económicas, con la debacle económica que se produjo a raíz de la crisis energética de los años setenta el sprawl de pronto pasó a ser un problema menor. Sin embargo, cuando la construcción recobró su dinamismo durante los años ochenta y noventa, se reavivó la preocupación por el sprawl, y en vista de que el aumento del bienestar económico en las últimas décadas del siglo XX fue mucho mayor y bastante más extendido en el mundo, el movimiento antisprawl adquirió más importancia que nunca y adoptó un carácter internacional a medida que observadores de todo el globo veían que el desarrollo suburbano y el progresivo incremento del número de dueños de automóvil originaba cambios sin precedentes en el paisaje. Como era de esperar, volvieron a formularse todos los mismos reparos en contra del sprawl, pero ahora con renovado dramatismo al incorporarse una nueva serie de argumentos ambientales, en particular la noción de que el sprawl suburbano era responsable del aumento en el consumo de energía, del aumento en el tráfico, de los mayores índices de contaminación, de las mayores concentraciones de gases de efecto invernadero y del calentamiento global. Según el lobby anti-sprawl, ya no se trataba de un fenómeno antieconómico y de mal gusto, sino que además representaba una amenaza para el planeta.

Sin embargo, la verdad es que, como de costumbre, los argumentos en contra del sprawl no resisten un análisis detallado. Por ejemplo, el calentamiento global no es provocado por el sprawl, y detener el sprawl no permitiría acabar con ese problema ambiental, o tal vez ni siquiera reducirlo, 


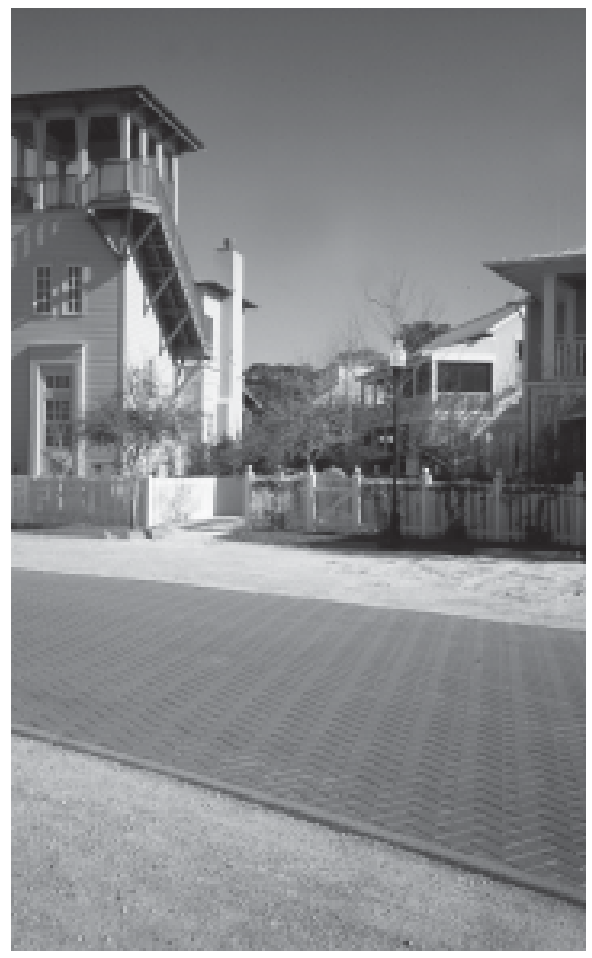

Foto 3: El Nuevo Urbanismo.

Andrés Duany y otros miembros del llamado Nuevo Urbanismo han criticado sistemáticamente el diseño habitual del suburbio y sprawl estadounidenses. Estiman que los suburbios no fomentan el sentido de comunidad y obligan a hacer numerosos viajes en automóvil. En sus propios diseños, en cambio, intentan incorporar las lecciones extraídas de las ciudades pequeñas y tradicionales de los EE.UU. La inauguración de Seaside Resort, en el estado de Florida, diseñado a inicios de los años ochenta por la firma de Duany Plater-Zyberk \& Company, causó sensación porque algunas personas lo vieron como una alternativa a las urbanizaciones y sprawl acostumbrados. Sin embargo, la mayoría de las urbanizaciones realizadas por el Nuevo Urbanismo tienen una densidad bastante baja y están situadas en la periferia urbana. La pregunta es si el Nuevo Urbanismo constituye en verdad una alternativa a la expansión suburbana o es sólo una variante diseñada con buen gusto. (ㄷ The University of Chicago, 2005. Fotografía de Robert Bruegmann, 2000).

sin dejar a millones de habitantes urbanos sumidos en una abyecta pobreza. El mayor culpable del calentamiento global es el persistente uso de combustibles fósiles como principal fuente energética en todo el mundo. Detener todo sprawl en el futuro, aun en el caso de que ello fuera posible, no solucionaría el problema del calentamiento global. Ni siquiera se tiene certeza de que el hecho de obligar a todos a vivir en zonas de mayor densidad se 
traduzca en un menor consumo de energía y en una disminución de las emisiones de gases de efecto invernadero. Los factores más importantes en cuanto al consumo de energía y las emisiones de gases de efecto invernadero a nivel mundial parecen ser el nivel de vida y el clima local, y no el patrón de los asentamientos. Si las predicciones de los científicos sobre el cambio climático son correctas, no cabe duda de que será preciso adoptar algunas medidas radicales respecto a las emisiones de gases de efecto invernadero. Tratar de obligar a las personas a reasentarse en ciudades de alta densidad, como las que fueron construidas en el siglo XIX, difícilmente ayudará a mejorar la situación e, incluso, podría empeorarla.

\section{Tercera parte:}

\section{Remedios para el sprawl}

Supongamos, por un momento, que estoy completamente equivocado y que el sprawl es un problema gravísimo que es preciso contener. ¿Podríamos hacerlo? ¿Cuáles serían las consecuencias?

Afortunadamente disponemos de varios experimentos que se extendieron por largos períodos y que nos permiten apreciar los resultados de los intentos por detener el sprawl. El más importante fue aquel que se inició en Gran Bretaña inmediatamente después de la Segunda Guerra Mundial. En vista de la emergencia creada por el devastador conflicto, el nuevo gobierno laborista pudo poner en práctica algunas novedosas y radicales reformas al uso del suelo. Estas políticas fueron consecuencia directa de todas las campañas en contra del sprawl emprendidas por planificadores, arquitectos y otros profesionales antes de la guerra. El gobierno les confirió a estos planificadores, a nivel nacional y metropolitano, un grado de poder sin precedentes para detener el sprawl. Y luego, para garantizar la implementación de sus nuevos planes, adoptó la draconiana medida de nacionalizar el derecho de desarrollar el suelo urbano.

El plan más famoso para detener el sprawl fue el aplicado en el área metropolitana de Londres. En realidad, el Plan para Londres, de Patrick Abercrombie, había sido concebido durante la guerra y publicado en 1944. La amplitud de los nuevos poderes que se arrogó el Estado después de la guerra permitió que Abercrombie y sus colegas pusieran en práctica lo dispuesto por el plan. Según el documento de Abercrombie, Londres, que en ese entonces seguía siendo considerado de manera casi unánime como una ciudad con un casco urbano excesivamente denso, continuaría descentralizándose, pero sólo hasta cierto punto. Abercrombie había trazado en su 
plan una línea circular para indicar el inicio de un cinturón verde con el que se pretendía otorgarle a la ciudad un contorno y un límite coherentes. No se permitiría ninguna edificación dentro del cinturón verde. En caso de necesitarse terrenos adicionales para asentamientos, proyectó un conjunto de ciudades jardín pequeñas y autosuficientes que se localizarían en una zona agrícola más allá del cinturón verde, sobre la base de un modelo propuesto a comienzos del siglo XX por el reformador Ebenezer Howard.

Las más importantes disposiciones anti-sprawl del plan de Londres están vigentes desde entonces, y de hecho se han vuelto más rigurosas durante los últimos años, lo cual nos permite extraer algunas conclusiones acerca de su eficacia y consecuencias. La primera pregunta, desde luego, es si el plan de Londres realmente logró detener el sprawl. Es posible encontrar una manera de responder afirmativamente. Por cierto, el cinturón verde alrededor de Londres aún se mantiene. Algunos podrían considerar que proporcionar un contorno claro y definido al centro de esa ciudad constituye un triunfo estético. Con todo, el cinturón verde no logró contener a Londres. El crecimiento demográfico y, sobre todo, el crecimiento económico fueron mucho mayores que lo previsto por Abercrombie. Una vez que los terrenos entre el centro de la ciudad y el inicio del cinturón verde se agotaron, comenzaron a construirse viviendas más lejos aún, más allá del límite exterior del cinturón. Como resultado de lo anterior, una vasta extensión del sudeste de Inglaterra ha sido urbanizada, y podría afirmarse que gracias a ello el sprawl se ha extendido aun más de lo que habría sucedido sin el cinturón verde. Por añadidura, como consecuencia de la nacionalización de los derechos de urbanización, de las restricciones impuestas por el cinturón verde a la oferta de terrenos y de la aplicación de todo tipo de reglamentaciones, la construcción de viviendas disminuyó bruscamente, subió el precio de los terrenos y los tiempos de desplazamiento alcanzaron uno de los niveles más altos de Europa ${ }^{6}$.

Ello no quiere decir que las medidas anti-sprawl no puedan producir el efecto deseado. En muchos lugares donde no existe un mercado del suelo, o donde los habitantes tienen muy pocas posibilidades de decidir dónde vivir o trabajar, las medidas anti-sprawl del tipo propugnado por Patrick Abercrombie han arrojado resultados que se acercan mucho más a lo que él ambicionaba. Por ejemplo, en la Unión Soviética, en ciudades como Moscú o San Petersburgo, los planificadores lograron establecer cinturones verdes y otras políticas que surtieron efecto y no llegaron a tener las consecuencias indeseadas que se han observado en el Occidente democrático. De

${ }^{6}$ El estudio más exhaustivo sobre los efectos del sistema de planificación británico puede encontrarse en Peter Hall y otros, The Containment of Urban Britain, 1973. 
hecho, la planificación urbana en estos lugares representa un triunfo considerable, habida cuenta del estado de enorme pobreza y subdesarrollo en que se encontraban esas ciudades. Empero, tal como ocurrió en Occidente, el éxito tuvo un costo, que en este caso fue la necesidad de restringir drásticamente la libertad individual, la capacidad de una familia común para escoger dónde deseaba vivir o trabajar.

Los resultados imprevistos e incluso los fiascos del plan de Londres parecen haber señalado el camino que seguirían esfuerzos similares realizados en cualquier otro lugar del mundo desarrollado, desde Portland, Oregon, en los Estados Unidos, hasta Auckland, en Nueva Zelanda. Si bien son contados los casos en que esas medidas han logrado detener el sprawl, al parecer sí han tenido algún éxito en hacer subir el precio de los terrenos. Lo anterior ha dado lugar a una creciente oposición a las políticas antisprawl. En los Estados Unidos esa oposición ha provenido en gran parte del ala derechista libertaria del espectro político, quienes consideran que esas políticas son intervenciones injustificadas del Estado, ineficaces o incluso contraproducentes, en asuntos que sería preferible confiar a las fuerzas del mercado. En Canadá, en Europa y en Australia, la oposición ha provenido con igual frecuencia de la izquierda política, por parte de quienes piensan que los planes para gestionar el crecimiento obedecen a criterios estéticos de la clase media alta que han impuesto penurias excesivas a los ciudadanos más desfavorecidos y hacinados en altas densidades en aquellos sectores que cuentan, precisamente, con menos instalaciones y servicios.

La conclusión a la que llegué en mi libro no fue que el sprawl sea algo bueno, sino sólo que no es necesariamente algo malo. Sostuve que, por lo que pude apreciar, los inconvenientes del sprawl no eran forzosamente peores que los problemas que aquejan a las ciudades de alta densidad. También argumenté que el sprawl es una herramienta de diagnóstico muy deficiente, pues agrupa en una misma categoría problemas que guardan directa relación con el sprawl, a saber, aquellos asociados al hábitat animal, junto con problemas que en el mejor de los casos sólo tienen una conexión tangencial —por ejemplo el calentamiento global—y problemas que no tienen casi nada que ver con el sprawl, por ejemplo la absurda aseveración de que vivir en los suburbios causa obesidad.

Asimismo argüí que el sprawl distraía nuestra atención de los verdaderos problemas de las ciudades, por ejemplo la suerte que corren millones de habitantes urbanos que viven en asentamientos informales en el mundo en desarrollo, y que se están muriendo por decenas de miles debido a que no cuentan con agua potable ni con instalaciones para el tratamiento de aguas servidas. Igualmente sostuve que, como condición básica, debería- 
mos aclarar por qué el sprawl fue tan beneficioso para tanta gente durante un período tan prolongado, y por qué nuestros esfuerzos para detenerlo podrían generar problemas peores que el mismo sprawl.

\section{DESARROLLOS RECIENTES}

Desde que mi libro fue publicado y comencé a dar conferencias en varias ciudades de todo el mundo he aprendido mucho más; también se han hecho no pocos avances en el estudio del sprawl. El suceso más importante, con todo, es un cambio significativo en la manera de percibir el sprawl. Aun cuando no tengo claro en qué medida mi libro contribuyó a este cambio o fue un mero síntoma de él, da la impresión de que hoy en día cada vez más personas advierten que muchísimas cosas que la mayoría suponía conocer acerca del sprawl han quedado en tela de juicio.

En numerosas publicaciones recientes ya se ha dejado de lado la presunción de que el sprawl es pernicioso y que, por ende, es necesario pasar directamente a las estrategias para detenerlo. El concepto, al menos, se ha transformado en objeto de acalorado debate. Ello queda de manifiesto en el título del libro publicado en 2006 por el periodista Anthony Flint: Our Land. The Debate Over Sprawl. En esta obra Flint reconoce este proceso, pese a que paralelamente tiende a tomar partido por las opiniones establecidas acerca de los perjuicios que acarrea el sprawl. Mucho más crítico frente a las verdades establecidas es el libro de William T. Bogart, también publicado en 2006, titulado Don't Call it Sprawl. Y existe una visión más matizada en la obra de Richard Ingersoll, Sprawltown: Looking for the City on its Edges, publicada, al igual que las anteriores, en 2006, lo mismo que en una serie de estudios realizados por Policy Exchange en Gran Bretaña, en los cuales se compara la manera en que las políticas más flexibles aplicadas por países como Alemania y Suiza han funcionado, en varios aspectos, mucho mejor que el régimen de planificación más rígido vigente en Gran Bretaña7.

Además del trabajo de los observadores, que ha arrojado nuevas luces sobre numerosos aspectos relacionados con las supuestas verdades sobre el sprawl, en el mundo desarrollado también han aparecido varias publicaciones en las que se cuestionan de manera muy directa los diagnósticos y las recomendaciones anti-sprawl. En un solo año, 2006, aparecieron

\footnotetext{
${ }^{7}$ Véase, por ejemplo, Alan W. Evans y Oliver Marc Hartwich, "Bigger Better Master More”, septiembre de 2005 en http://www.policyexchange.org.uk/ Publications.aspx?id=161.
} 
The Planning Penalty, de Randal O'Toole, y War on the Dream: How AntiSprawl Policy Threatens the Quality of Life, de Wendell Cox, en los Estados Unidos; Let's Build: Why We Need Five Million New Homes in the Next 10 Years, de James Heartfield, en Gran Bretaña; y The Tragedy of Planning: Losing the Great Australian Dream, de Alan Moran, en Australia. A veces estas obras son tan polémicas como los propios manifiestos anti-sprawl, pero, sin duda, ponen en entredicho muchas de las premisas básicas de la cruzada anti-sprawl.

Otro aspecto que al parecer resulta cada vez más evidente es que las políticas anti-sprawl contraen la oferta de terrenos y aumentan el precio de las viviendas. En un estudio anual en gran escala sobre la capacidad para adquirir una vivienda en el mundo angloparlante, Wendell Cox y Hugh Pavletich han proporcionado cifras relativas a la razón entre el precio promedio de una vivienda y el ingreso promedio en las principales ciudades de Estados Unidos, Canadá, Gran Bretaña, Irlanda, Australia y Nueva Zelanda ${ }^{8}$. Los resultados son extremadamente reveladores. En muchas de las ciudades sometidas a las más férreas regulaciones, como Los Ángeles, Vancouver, Londres o Sydney, la razón del precio promedio de la vivienda con el ingreso promedio se ha elevado notoriamente, llegando a niveles que al parecer no tienen precedentes en la historia moderna. Al mismo tiempo, algunas de las ciudades de más rápido crecimiento y más dinámicas de Norteamérica, en las que no se han aplicado esas normas tan intrusivas, han mantenido niveles asequibles con razones cercanas a 2 ó 3, lo que hasta no hace mucho parecía ser la norma en la mayoría de las ciudades.

La fecha en que comienzan a regir las regulaciones es reveladora. La mayoría de las ciudades de Estados Unidos y de Canadá donde hoy resulta tan caro vivir, por ejemplo Los Ángeles con su razón de 11,5 en 2007, o San Francisco con 10,8, no eran tan caras hasta los años setenta, cuando sobrevino la oleada más reciente de regulaciones relativas al medio ambiente, el patrimonio y la gestión del crecimiento urbano. Aun cuando hay muchos otros factores que potencialmente podrían haber contribuido a que el precio de las viviendas se disparara durante los últimos años, resulta muy difícil pasar por alto el estrecho vínculo que parece existir entre regulación y precio de las viviendas, especialmente en países como Australia o Nueva Zelanda, donde claramente no hay escasez de terrenos, pero donde hace pocos años se comenzaron a aplicar con especial entusiasmo técnicas británicas de gestión del crecimiento urbano.

${ }^{8}$ El índice anual de capacidad adquisitiva de Demographia puede encontrarse en el sitio web de Demographia en http://www.demographia.com/dhi.pdf. 
Un viaje que efectué recientemente a Hong Kong me hizo advertir claramente este tema. Debido a que tanto durante el dominio británico como ahora, bajo la autoridad de China, los planificadores en Hong Kong no han estado sometidos al mismo grado de autoridad democrática que los ciudadanos británicos, se han podido poner en práctica regulaciones de planificación anti-sprawl muchísimo más estrictas que las de la propia Gran Bretaña. El resultado ha sido un sistema en el que la densidad del casco urbano y de los nuevos poblados construidos en la periferia se mantiene en niveles extremadamente altos para conservar la mayor parte de los terrenos como espacio público abierto. Como consecuencia de lo anterior, los sectores urbanizados de Hong Kong, con cerca de 294 habitantes por hectárea, exhiben la que, casi con certeza, es la densidad promedio más alta de todas las áreas urbanas del mundo, sin duda varias veces superior a la de cualquier otra zona urbana del mundo desarrollado. Es este hecho el que aparece como el factor más importante de otro ámbito en el que Hong Kong constituye una excepción entre las demás ciudades del mundo. El precio promedio de una unidad de vivienda promedio, un departamento de $45 \mathrm{~m}^{2}$ en un edificio de veinte pisos, fluctúa entre US\$300.000 y US\$500.000.

Por último, desde la aparición de mi libro he estudiado las aseveraciones de los ambientalistas, en particular aquellas según las cuales las ciudades con un casco urbano denso son más sustentables que los asentamientos de baja densidad. Me asombra lo ligeras que suelen ser esas argumentaciones. Por ejemplo, la mayoría de quienes se oponen al sprawl ha sostenido que, incluso con densidades típicas de los suburbios, la superficie de terrenos impermeables es tan grande que facilita las inundaciones y contribuye a deteriorar la calidad del agua. Así pues, a su juicio, el patrón óptimo corresponde a una ciudad y a una zona suburbana densas, con escaso desarrollo más allá de ellas. Al consultar a especialistas en hidrología, sin embargo, queda de manifiesto que esos argumentos se basan en supuestos inexactos. La noción de que la única manera de deshacerse de las aguas servidas y residuales es crear costosos y centralizados sistemas de alcantarillado y plantas de tratamiento, a semejanza de los construidos en el siglo XIX, no ha sido respaldada por la evidencia. Salvo en zonas de altas densidades, hay numerosas cosas que se pueden hacer con los jardines pluviales y con otros elementos diseñados para captar el agua y permitir que se vuelva a filtrar a la tierra de manera mucho más natural, en vez de almacenarla y enviarla a gigantescas plantas de tratamiento. Asimismo, en urbanizaciones de muy baja densidad, el uso de pozos y los "sistemas de montículo" de tecnología avanzada para el trata- 
miento de aguas servidas dan excelentes resultados a una fracción del costo de los grandes sistemas centralizados.

También he investigado más a fondo la suposición de que los habitantes urbanos consumen menos energía que quienes viven en suburbios de baja densidad. Si bien ello puede ser cierto en términos generales, da la impresión de que ese argumento ha sido dramáticamente exagerado. Muchos de los estudios realizados se limitaron a emplear información sobre consumo de energía aportada por un grupo de habitantes de departamentos, y luego la comparaban con datos equivalentes proporcionados por un grupo de residentes en casas unifamiliares. En cambio, una investigación mucho más precisa realizada por el estado de Nueva Gales del Sur, dentro del cual se encuentra Sydney, en Australia, determinó el consumo total de energía en edificios de departamentos sobre la base de información facilitada por empresas de servicio público, la que se comparó con el consumo total de las casas. Lo que se descubrió fue que los habitantes de casas unifamiliares consumían, en términos per cápita, menos energía y producían menos emisiones de gases de efecto invernadero que quienes residían en departamentos $^{9}$. Si bien a primera vista cuesta comprenderlo, se entiende claramente cuando se considera que los edificios de departamentos suelen tener ascensores, que en ellos las luces permanecen encendidas las 24 horas del día y que muchos cuentan con sistemas de calefacción central que de manera periódica deben suministrar suficiente agua caliente o fría para calefaccionar o enfriar los pisos de más difícil acceso, lo cual significa que están empleando una gran cantidad de agua caliente o fría que no requieren los demás pisos. Ello explica, a su vez, el hecho de que no sea raro observar ventanas abiertas en el sector soleado de un edificio, incluso durante días muy fríos.

\section{ALGUNAS NOTAS SOBRE SANTIAGO}

Todo parece indicar que el proceso de descentralización y de sprawl se ha transformado en un fenómeno universal para los ciudadanos de clase media de todo el mundo, dondequiera que exista algo semejante a un proceso político abierto o a un mercado del suelo. Esta situación también parece observarse en ciudades latinoamericanas, pero desgraciadamente la documentación disponible para esta región es mucho menos completa que para ciudades de Norteamérica y Europa. Pero el panorama está comenzando a

9 “Multi-Unit Residential Building Energy and Peak Demand Study”, 2005. 
cambiar, desde luego en Santiago, donde el CEP ha hecho una contribución importante ${ }^{10}$.

Al parecer, a lo largo de varios años Santiago ha estado perdiendo densidad en su casco urbano y expandiéndose hacia las zonas rurales circundantes. Quizás lo más interesante acerca de Santiago es que el crecimiento económico de los últimos años le permite hoy estar a punto de transformarse en una ciudad del próspero primer mundo.

Una de las diferencias más importantes entre las ciudades del mundo en desarrollo y del mundo desarrollado es que en la mayoría de las primeras las familias siguen abandonando las zonas rurales y fluyen a las ciudades en grandes oleadas, mientras que en el mundo próspero este proceso se ha detenido en gran medida y la población urbana y rural se ha mantenido en niveles bastante estables. Como consecuencia de lo anterior, en el mundo en desarrollo, ya sea en Ciudad de México, São Paulo, Lagos, Yakarta o Mumbai, ha tenido lugar una explosión demográfica que supera con creces la capacidad de la ciudad para acoger a los recién llegados. Por lo general éstos se establecen en asentamientos informales de muy alta densidad. La mayoría de los gobiernos ha intentado retardar o detener este proceso, trasladando a los nuevos habitantes a viviendas recién construidas y más definitivas.

En Santiago el proceso de migración campo-ciudad parece haberse completado, y cabe destacar que casi todos sus actuales habitantes se encuentran establecidos en urbanizaciones definitivas, es decir en aquellas en que la mayoría de las viviendas cuentan con agua potable, electricidad y todas las instalaciones sanitarias. Aun cuando distan mucho de ser primorosas y seguramente presentarán problemas con el paso de los años, el solo hecho de que estas viviendas hayan sido construidas constituye un enorme logro y un triunfo de la política pública.

La llegada de familias pobres desde las zonas rurales a ciertos sectores de alta densidad del área urbana ha sido compensada por un éxodo no menos importante de familias acomodadas y de clase media desde barrios del casco urbano hacia urbanizaciones de menor densidad situadas en la periferia. La densidad global de la zona urbana de Santiago asciende a aproximadamente 85 hab/ha, que es más o menos el nivel que cabría esperar, vale decir entre la densidad mucho mayor propia del mundo en desarrollo y la densidad considerablemente menor de numerosos lugares de Norteamérica y de Europa.

${ }^{10}$ Uno de los mejores libros publicados sobre el uso del suelo, aplicable a cualquier área metropolitana, es Santiago. Dónde Estamos y hacia Dónde Vamos, editado por Alexander Galetovic, con mapas de Iván Poduje, y publicado por el CEP el 2006. 
La densidad del área urbana de El Cairo, por ejemplo, es de más de 130 hab/ha; la de Bogotá y Medellín supera los 150 hab/ha, y la de Mumbai bordea los $200 \mathrm{hab} / \mathrm{ha}$. En el otro extremo, la densidad de las áreas urbanas de Phoenix, Houston o Atlanta no supera los 12 hab/ha. Con 85 hab/ha, la densidad de Santiago es similar a la de algunas de las ciudades más densas del mundo más desarrollado, por ejemplo Bruselas.

Esta cifra promedio encubre notorias diferencias entre distintos sectores de la ciudad. Uno de los resultados del arribo de nuevos residentes a las zonas más densas de la ciudad, situadas principalmente al sur y al poniente, y del éxodo de familias acomodadas hacia zonas cada vez menos densas, ubicadas comúnmente al norte y al oriente hasta ocupar los faldeos de la cordillera de los Andes, ha sido la creación de una ciudad partida en dos. El casco histórico, lo que se conoce como Santiago Centro, se sitúa ahora entre estas dos ciudades, tan distintas una de la otra.

Las zonas pobres de alta densidad siguen conservando un aspecto muy similar al de sus equivalentes en el mundo en desarrollo, mientras que las zonas más prósperas en vías de expansión se asemejan cada vez más a ciudades del primer mundo con un clima similar, por ejemplo Los Ángeles o Sydney. El área de mayor poder adquisitivo de Santiago, que se concentra alrededor de Providencia, Vitacura y Las Condes, se ha desarrollado como una ciudad casi completamente aparte. Si bien una gran cantidad de instituciones y empresas siguen funcionando en el centro, el núcleo económico del área urbana se ha ido trasladando progresivamente hacia el sector nororiente, y también se ha dispersado. $\mathrm{Y}$ aun cuando su epicentro quizás se encuentre hoy en el complejo Costanera Center, se ha diseminado por toda el área más próspera y hacia las nuevas urbanizaciones situadas en zonas mucho más alejadas.

Este proceso ha sido similar al que ha tenido lugar en otras ciudades latinoamericanas. Por ejemplo en Ciudad de México, donde el éxodo se ha producido desde el Zócalo hacia las zonas más prósperas situadas al Sudoeste a lo largo del Paseo de la Reforma, y ahora se expande hacia Santa Fe. O en São Paulo, donde las grandes empresas y las familias más acomodadas se trasladaron primero desde el casco histórico hasta la avenida Paulista, y ahora se están mudando a sectores aún más retirados. Sin embargo, de todos esos enclaves latinoamericanos de altos recursos, el de Santiago es casi con certeza el más extenso en relación con el área urbana en su conjunto. De hecho, éste es el único sector del área metropolitana que llegan a conocer muchos de quienes visitan la ciudad. Con sus centros comerciales, centros de negocios, elegantes edificios de departamentos y 
viviendas unifamiliares, esta zona de Santiago puede compararse favorablemente con casi todos los barrios urbanos más distinguidos de cualquier ciudad del mundo.

En lo que respecta al sector más desfavorecido del área urbana, uno de los desafíos más importantes será integrar a las familias más pobres a sectores más amplios de la sociedad y de la economía. En varios aspectos, el reto para Santiago resulta menos intimidatorio que el que deben encarar muchas ciudades más grandes. En Santiago ya no se observa el clima de agitación causado por la inmigración masiva a la ciudad. Tampoco alberga las enormes barriadas y poblaciones marginales, típicas de muchas ciudades del mundo en desarrollo, ni las grandes extensiones de elevados bloques de viviendas públicas que fueron construidos en todo el mundo a mediados del siglo XX. Obviamente existe una gran cantidad de viviendas sociales que tendrán que ser ampliadas, mejoradas o reemplazadas, pero como la mayoría de ellas son unifamiliares y están situadas en edificios de pocos pisos, tal vez el proceso resulte mucho más sencillo que en otras ciudades.

Uno de los aspectos más notables de la historia de numerosas ciudades del mundo desarrollado es la gran cantidad de viviendas que fueron consideradas anticuadas durante las décadas posteriores a la Segunda Guerra Mundial, de calidad inferior al promedio o sin arreglo posible. Los programas estatales de renovación urbana lograron mejorar algunas, pero a menudo crearon nuevos tipos de viviendas que a poco andar también quedaron por debajo de los estándares aceptados. Con todo, en vastos sectores donde no se habían aplicado programas públicos, cada propietario, a medida que adquiría un mayor bienestar económico, fue capaz de reparar y mejorar su vivienda, de modo que muchos kilómetros cuadrados de edificaciones otrora consideradas una lacra urbana, se han transformado en una zona muy atractiva para vivir.

En Chile, al igual que en tantos otros países del mundo, las políticas estatales de planificación urbana algunas veces hacen mucho bien, pero a menudo son ineficaces e incluso perjudiciales. Santiago continúa expandiéndose hacia las afueras, en particular mediante la construcción de grandes y planificadas urbanizaciones en los extramuros, a pesar de que en Chile, desde hace ya largo tiempo, los planificadores han seguido el ejemplo de sus colegas de países más ricos en cuanto a intentar controlar el crecimiento de la ciudad estableciendo límites. Como ocurre en la mayoría de las ciudades más prósperas, las restricciones al crecimiento sólo han tenido un efecto muy leve. A medida que la población ha ido aumentando y se ha 
expandido hasta forzar los límites de la ciudad, estos límites han sido rediseñados o relajados. Se trata probablemente de una manera pragmática y eficaz de controlar en algún grado el desarrollo del área metropolitana, de facilitar el suministro oportuno de infraestructura, y al mismo tiempo permitir que el mercado inmobiliario realice una tarea en la que tradicionalmente ha demostrado mayor pericia que los planificadores estatales: prever aspiraciones y necesidades futuras.

Una planificación sensata junto a políticas de uso del suelo prudentes pueden resultar fundamentales para que Santiago siga progresando. La espectacular ubicación topográfica de la ciudad, su fácil acceso a las montañas y al mar, su clima razonablemente benigno, al igual que su crecimiento económico durante los últimos años, constituyen enormes ventajas. El rápido crecimiento del tráfico aéreo de larga distancia permitiría superar fácilmente una de las principales desventajas del pasado, que era su ubicación en una zona muy alejada del resto de los grandes centros de población del mundo. Para facilitar el crecimiento y atraer la inversión, será requisito esencial fomentar la igualdad social, mejorar las condiciones ambientales, conservar los espacios abiertos y las zonas de valor paisajístico tanto al interior de la ciudad como en sus alrededores, como también proporcionar la infraestructura necesaria para mantener y aumentar el grado de movilidad al tiempo que muchos más chilenos acceden a un nivel socioeconómico que les permite adquirir y utilizar automóviles.

Este proceso puede apreciarse en ciudades del mundo exitosas. Singapur y Hong Kong ofrecen buenos ejemplos de cómo, gracias a una cuidadosa planificación y una cuantiosa inversión en infraestructura, educación y programas sociales, ciudades sin muchos recursos al alcance de la mano y muy alejadas de los tradicionales centros económicos mundiales, han sido capaces de transformarse en eficaces motores económicos y en lugares atractivos para vivir y trabajar. Por otra parte, la importancia de un clima benigno y de un magnífico entorno geográfico queda de manifiesto en ciudades como Sydney, Perth y Vancouver, que sólo recientemente, gracias al masivo aumento de los viajes aéreos internacionales, han logrado incorporarse al mapa mundial mental de incontables personas.

La lección que Santiago podría aprender de la experiencia de ciudades del mundo próspero es que el afán excesivo por controlar el contorno y la configuración de la ciudad y por detener lo que parece ser un patrón de desarrollo caótico a medida que las familias procuran abandonar el casco urbano, probablemente creará más problemas que los que resolvería.

Por otra parte, da la impresión de que los problemas han sido sobredimensionados. El riesgo de que este fenómeno de descentralización 
reduzca de manera considerable la cantidad de tierra disponible para cultivos en el país es mínimo. Tampoco hay motivos fundados para temer que este proceso vaya a terminar por invadir todas las zonas agrícolas. Si las lecciones extraídas de Los Ángeles y las ciudades del sudoeste de los Estados Unidos nos dan algún indicio, tal parece ser que en determinado momento la densidad deja de disminuir y comienza a aumentar nuevamente. Por otro lado, los intentos de restringir el crecimiento en las afueras de la ciudad casi siempre tenderán a retardar la movilidad económica y social y a provocar un alza en el costo de las viviendas para todas las personas, lo que perjudica en especial a las familias de bajos ingresos.

Sin duda que una de las posibilidades más interesantes y esperanzadoras que ofrece la larga historia del sprawl es la renovación (gentrification) del centro de Santiago. En la medida en que las familias de bajos recursos continúen abandonando el centro, disminuyan las densidades y se haga frente a los problemas ambientales, hay razones suficientes para creer que esta zona, con su enorme inversión en infraestructura, su atractivo patrimonio de construcciones históricas y su concentración de lugares de interés cultural, logrará seducir a algunos habitantes que, de lo contrario, seguirían emigrando a Vitacura, Las Condes y sectores más alejados. Todo parece indicar que este proceso está en marcha.

\section{REFERENCIAS}

Bruegmann, Robert: Sprawl: A Compact History. University of Chicago Press, 2005.

Clark, Colin: “Urban Population Densities”. En Journal of the Royal Statistical Society, Vol. 114 (1951).

- Population Growth and Land Use. Nueva York: Macmillan, 1977.

Demographia. Sitio web www.demographia.com/dhi.pdf.

Echenique, Marcial y Andrew Saint: Cities for the New Millennium. Londres: Spon Press, 2001.

Evans, Alan W. y Oliver Marc Hartwich: "Bigger Better Master More”, septiembre de 2005. En http://www.policyexchange.org.uk/Publications.aspx?id=161.

Galetovic, Alexander (ed.): Santiago. Dónde Estamos y hacia Dónde Vamos. Santiago: CEP, 2006.

Garreau, Joel: Edge City: Life on the New Frontier. Nueva York: Doubleday, 1991.

Hall, Peter et al. (eds.): The Containment of Urban Britain. London: PEP, 1973.

Jackson, Kenneth: Crabgrass Frontier: The Suburbanization of the United States. Oxford: Oxford University Press, 1985.

“Multi-Unit Residential Building Energy \& Peak Demand Study”. Energy News, Vol. 23, 2005. 
Nivola, Pietro: Laws of the Landscape: How Policies Shape Cities in Europe and America. Washington D. C.: Brookings Institution, 1999.

Sievert, Thomas: Cities Without Cities: An Interpretation of the Zwischenstadt. Londres: Spon Press, 2003. 